The International Journal Of Engineering And Science (IJES)

|| Volume || 6 || Issue || 2 || Pages || PP 42-45 || 2017 ||

ISSN (e): $2319-1813 \operatorname{ISSN}$ (p): $2319-1805$

THE IJES

\title{
Retrospective and Prospective Studies of Gastro-Intestinal Helminths of Humans and Dogs in Makurdi, Nigeria
}

\author{
I.I. Luga, A.R. Dada and R. A. Ofukwu \\ Department of Veterinary Public Health and Preventive Medicine, College of Veterinary Medicine, University \\ of Agriculture, Makurdi, Nigeria.
}

\begin{abstract}
-
A five-year retrospective and one-year prospective studies of gastrointestinal (GIT) helminths was carried out in humans and dogs in Makurdi, Nigeria. Data from 534 individuals presented at the Federal Medical Centre (FMC) and 103 faecal samples from dogs at the Veterinary Teaching Hospital (VTH), University of Agriculture, Makurdi from 2007 to 2014 were used. The overall prevalence of zoonotic GIT helminths in humans was $76.21 \%$ (407/534) and $56.31 \%(58 / 103)$ in dogs. The differences in the prevalences in humans based on sex,ethnicity and age were not statistically significant $\left(\chi^{2}, P<0.05\right)$. However, the test of individual factor (coefficient) on GIT helminthes in humans showed that hookworms prevalence was dependent on age $(P=$ $0.001)$, Ascaris lumbricoides was dependent on ethnicity and age $(P=0.000$ and 0.005$)$, Taenia spp. prevalence was dependent on age and sex $(P=0.007$ and 0.005$)$, and Strongyloides stercoralis prevalence was dependent on age $(P=0.04)$. The prevalence in dogs depended on age and breed $\left(\chi^{2}, P<0.05\right)$ but not on sex $\left(\chi^{2}, P>\right.$ 0.05). Hookworms, Taenia spp and Trichuris vulpisoccurred in humans and dogs. Hookworms were the most common helminth of both humans and dogs. Individual factor (coefficient) on the effect of risk factors on specific helminths is essential in understanding the epidemiology of each helminth. Attention should be paid to control measures in man anddogs.
\end{abstract}

Keywords: Prevalence, Helminths, Risk factors, Makurdi.

Date of Submission: 22 August 2016

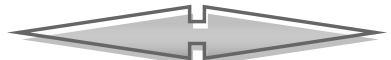

Date of Accepted: 25 February 2017

\section{INTRODUCTION}

A large number of diseases that are endemic in sub-Saharan Africa have been overlooked even by local health authorities who have along with international health systems, made these diseases to be labelled as neglected tropical diseases (NTD) (Hotez et al., 2008; Hotez and Kamath, 2009). A vast majority of these diseases affect mostly the very poor and are often co -endemic with malaria and HIV/AIDS (Hotez, 2011). The typical abandoned diseases are zoonotic gastro-intestinal, soil-transmitted helminths infections (Hotez et al., 2007, 2008).

These infections are prevalent in Nigeria, especially in children living where adequate water and sanitation facilities are lacking (Abah and Arene, 2015, Odinaka et al., 2015). It has been observed that children living under such conditions can be chronically infected with several species of helminths (Hotez et al., 2008; Usip and Mathew, 2015). Chronic helminth infections result in anaemia, stunted growth, under-nutrition, reduced work efficiency and poor cognitive development (long-term disability and poverty) (Hotez et al., 2007, 2008). This ignored morbidities enhance malaria (Mwangi et al., 2006).

The high prevalence rates haveled to the estimation of the worm burden using prevalence, (Usip and Matthew, 2015), instead of the classic measure by eggs per gram (EPG) of faeces and its association with morbidity (Hotez et al., 2008). Dogs have been implicated in the transmission of some human GIT heminths (Bownan $e t$ al., 2010; Deplazes et al., 2011; Ogbolu et al., 2011; Traversa et al., 2014). Contamination of the environmentdue to poor sanitary facilities and a high dog population prompted the study which should remind health authorities about the ever present status of these neglected diseases in Nigeria.

\section{MATERIALS AND METHODS}

Retrospective and prospective studies of zoonotic GIT helminthes of humans and dogs were carried out at The Federal Medical Center (FMC) and Veterinary Teaching Hospital, (VHT), University of Agriculture, Makurdi, respectively. The case-control study involved retrieving data from the general out-patient department (GOPD), the medical records archive and laboratory sections of the hospital from January, 2007 to December 2012. The prospective study was carried out by systematically collecting faecal samples per rectum from dogs presented at the VTH Makurdi every Tuesday and Thursday from April 2013 to March 2014. The faecal samples were analysed using the salt floation technique (Zajac and Conboy, 2012). 
Retrospective And Prospective Studies Of Gastro-Intestinal Helminths Of Humans And Dogs In...

Age, sex, ethnic group and type of parasite were the parameters used for retrieving data in the retrospective study while age, sex and breed were used in the prospective study. A sample size of 310 was arrived at using the method of Thrushfield (1995). Ethical clearance to conduct the study was obtained from the Ethical Committee, FMC Makurdi. The data generated from the study was analysed using the Statistical Package for Social Sciences (SPSS) for windows version 20.0. The Chi-square $\left(\left(\chi^{2}\right)\right.$ was employed to test for association between variables. Chi-square test of model coefficient for individual helminths was used to ascertain whether the prevalence of each helminth depended on specific risk factors. Where dependence was demonstrated, the test of individual factor coefficient was carried out to determine the significance of each risk factor to the prevalence of specific helminths. In all analyses statistical significance was taken to be at $(\mathrm{p}<0.05)$.

\section{RESULTS}

A total of 534 cases were retrieved for the five years retrospective study. The overall prevalence of zoonotic GIT helminths in humans at the FMC was 76.21\% (407/534). The year 2009 had the highest prevalence rate of $100 \%$ (Table 1). The distribution of the prevalence based on sex was $57.5 \%$ (234/407) for males and $42.5 \%$ $(173 / 407)$ for females. The difference was not statistically significant (p.>0.05). The 11-20 age group had the highest prevalence rate of $86.7 \%(91 / 105)$. The difference was not significant $(\mathrm{p}>0.05)$. The distribution based on ethnicity was $58.96 \%$ (24/407) Tiv, $15.72 \%$ (64/407) Idoma and 25.3\% (103/407) other Nigerian ethnic groups. The difference was not significant $(\mathrm{p}>0.05)$ (Table 2).

Table 1. Yearly prevalence and types of zoonotic helminths encountered at the FMC Makurdi (2007-2012)

\begin{tabular}{|c|c|c|c|c|c|c|c|}
\hline $\begin{array}{l}\text { Number } \\
\text { Examined/ Year }\end{array}$ & $\begin{array}{l}\text { H. worm } \\
\text { (No. +ve) }\end{array}$ & $\begin{array}{l}\text { Ascaris } \\
\text { (No. +ve) }\end{array}$ & $\begin{array}{l}\text { Taenia } \\
\text { (No. +ve) }\end{array}$ & $\begin{array}{l}\text { Trichuris } \\
\text { (No. +ve) }\end{array}$ & $\begin{array}{l}\text { S. Stercoralis } \\
\text { (No. +ve) }\end{array}$ & $\begin{array}{l}\text { S. Mansoni } \\
\text { (No. +ve) }\end{array}$ & $\mathrm{NP}$ \\
\hline $65 / 2007$ & 29 & 10 & 3 & 8 & 0 & 3 & $53(81.53)$ \\
\hline $162 / 2008$ & 50 & 21 & 14 & 6 & 10 & 0 & $101(62.34)$ \\
\hline $93 / 2009$ & 49 & 23 & 9 & 5 & 8 & 0 & $93(100)$ \\
\hline $90 / 2010$ & 33 & 16 & 11 & 0 & 10 & 0 & $70(77.77)$ \\
\hline $61 / 2011$ & 17 & 6 & 3 & 9 & 7 & 0 & $42(68.85)$ \\
\hline $63 / 2012$ & 26 & 7 & 0 & 2 & 8 & 4 & 47 (74.60) \\
\hline 534 & $204(50.12)$ & $83(21.37)$ & 40(9.09) & $30(7.37)$ & $43(10.31)$ & $7(1.71)$ & $407(76.21)$ \\
\hline
\end{tabular}

$\mathrm{NP}=$ Number positive. The figures in parenthesis are percentages calculated from column and row totals

Table 2. Distribution of Zoonotic helminths in humans Presented at FMC Makurdi (2007-2012)

\begin{tabular}{|c|c|c|c|c|c|}
\hline \multicolumn{2}{|l|}{ Variable } & No. Of Examined & Prevalence Status & Chi-Square & P-Value \\
\hline \multirow[t]{3}{*}{ Sex } & & & & & \\
\hline & Male & 289 & $234(57.5 \%)$ & \multirow[t]{2}{*}{102.375} & \multirow[t]{2}{*}{0.809} \\
\hline & Female & 245 & $173(42.5 \%)$ & & \\
\hline \multirow[t]{4}{*}{ Ethnicity } & & & & & \\
\hline & Tiv & 307 & $240(78.18 \%)$ & \multirow[t]{3}{*}{2.381} & \multirow[t]{3}{*}{0.304} \\
\hline & Idoma & 84 & $64(76.19 \%)$ & & \\
\hline & Others & 144 & $103(71.52 \%)$ & & \\
\hline \multirow[t]{8}{*}{ Age } & & & & & \\
\hline & $0-10$ & 89 & $62(69.70)$ & \multirow[t]{7}{*}{102.375} & \multirow[t]{7}{*}{0.6966} \\
\hline & $11-20$ & 105 & $91(86.67)$ & & \\
\hline & $21-30$ & 110 & $90(81.81)$ & & \\
\hline & $31-40$ & 114 & $90(78.94)$ & & \\
\hline & $41-50$ & 67 & $42(62.68)$ & & \\
\hline & $51-60$ & 35 & $19(54.28)$ & & \\
\hline & $>60$ & 14 & $13(92.86)$ & & \\
\hline
\end{tabular}

However, the Chi-square test of model coefficient for individual helminths showed that the prevalence of hookworms, Ascaris lumbricoides, Taenia spp. and Strongyloides stercoralis in humans depended on risk factors (Table 3). The test of individual factor (coefficient) on GIT helminths showed that the prevalence of hookworms was dependent on age $(\mathrm{p}=0.001)$, but independent of sex and ethnicity $(\mathrm{p}=0.140$ and 0.954$)$ respectively. Ascaris lumbricoides prevalence was dependent on ethnicity and age $(\mathrm{p}=0.000$ and 0.005$)$ but independent of sex $(\mathrm{p}=0.545)$. Taenia spp. prevalence was dependent on age and sex $(\mathrm{p}=0.007$ and 0.005$)$ but not ethnicity $(\mathrm{p}=0.366)$. Strongyloides stercoralis prevalence was dependent on age $(\mathrm{p}=0.004)$ but not sex or ethnicity ( $\mathrm{P}=0.05$ and 0.366$)$ (Table 4$)$. 
Retrospective And Prospective Studies Of Gastro-Intestinal Helminths Of Humans And Dogs In...

Table 3. Chi-Square test of Model Coefficients on Hookworms, Ascaris spp, Teania spp and Strongyloides spp.

\begin{tabular}{|l|l|l|l|l|}
\hline Helminths & & Chi-Square & DF & Sig \\
\hline Hookworms & Block & 72.279 & 3 & 0.007 \\
\hline & Model & 72.279 & 3 & 0.007 \\
\hline Ascaris spp & Block & 102.375 & 3 & 0.005 \\
\hline & Model & 102.375 & 3 & 0.005 \\
\hline Teania spp & Block & 89.955 & 3 & 0.02 \\
\hline & Model & 89.955 & 3 & 0.02 \\
\hline Strongylodies spp & Block & 76.955 & 3 & 0.02 \\
\hline & Model & 76.955 & 3 & 0.02 \\
\hline
\end{tabular}

Table 4. Test of Individual factor (Coefficent) Hookworms, Ascaris spp, Teania spp and Strongyloides spp

\begin{tabular}{|l|l|l|l|l|l|l|l|}
\hline Helminths & Variable & B & S.E & Wald & Df & Sig.(P) & Odds ratio \\
\hline Hookworms & Sex & .236 & .160 & 2.183 & 1 & .140 & 0.790 \\
\hline & Age & .007 & .023 & .102 & 1 & .001 & 1.903 \\
\hline & Ethnicity & .008 & .135 & .003 & 1 & .954 & 0.992 \\
\hline & Constant & .095 & .404 & .055 & 1 & .814 & 1.100 \\
\hline Ascaris spp & Sex & -.130 & .215 & .367 & 1 & .545 & .878 \\
\hline & Age & .000 & .030 & .000 & 1 & .005 & 1.719 \\
\hline & Ethnicity & -.011 & .180 & .004 & 1 & .000 & 1.590 \\
\hline & Constant & -1.426 & .539 & 7.007 & 1 & .008 & .240 \\
\hline Teania spp & Sex & .066 & .267 & .061 & 1 & .005 & 1.468 \\
\hline & Age & -.099 & .038 & .050 & 1 & .007 & 1.301 \\
\hline & Ethnicity & -.207 & .229 & .817 & 1 & .366 & .813 \\
\hline Strongyloides Spp & Constant & -8.444 & .672 & 7.524 & 1 & .006 & .158 \\
\hline & Sex & .066 & .267 & .061 & 1 & .05 & 1.68 \\
\hline & Age & -.009 & .038 & .050 & 1 & .04 & 1.801 \\
\hline
\end{tabular}

The helminths encountered in humans included hookworms (Ancylostoma spp.) $50.12 \%$, Ascaris lumbricoides $21.37 \%$, Taenia spp. 9.09\%, Trichuris vulpis 7.37\%, Strongyloides stercoralis $10.31 \%$ and Schistosoma mansoni $1.71 \%$ (Table 1 )

In the prospective study the overall prevalence of zoonotic GIT helminths in dogs was $56.31 \%(58 / 103)$. The prevalence was dependent on age and breed $(\mathrm{p}<0.05)$ but not on sex $(\mathrm{p}>0.05)$. Hookworms were the most commonly encountered helminths accounting for $89.7 \%$ (52/58), Toxocara canis $6.9 \%$ (4/58), Trichuris vulpis $1.72 \%$ (1/58), and Taenia spp. 1.72\% (1/58) (Table 5).

Table 5. Prevalence of Zoonotic Helminths Parasites Of Dogs In UAMVTH (March 2012-February, 2013)

\begin{tabular}{|l|l|l|l|l|l|l|l|}
\hline Variable & No Examined & No Positive & Prevalence & Odds ratio & Chi-Square & P-value \\
\hline Age & $0-2$ & 72 & 45 & $(88.23 \%)$ & 1.3 & 12.000 & 0.625 \\
\hline & $2-4$ & 9 & 5 & $(9.80 \%)$ & 1.6 & & 0.500 \\
\hline & $4-6$ & 3 & - & - & - & & \\
\hline & $>60$ & 2 & 1 & $(1.96 . \%)$ & - & & \\
\hline Breed & Mongrel & 31 & 20 & $64.52 \%$ & - & 2.8876 & 0.0893 \\
\hline & Exotic & 55 & 25 & $29.33 \%$ & - & & \\
\hline Sex & Male & 50 & 31 & $60.78 \%$ & 1.2 & 48.000 & 0.56 \\
\hline & Female & 38 & 17 & $33.33 \%$ & - & & \\
\hline Helminths & Hookworms & 103 & 52 & $89.66 \%$ & - & & \\
\hline & T. canis & 103 & 4 & $6.89 \%$ & - & & \\
\hline & T. vulpis & 103 & 1 & $1.72 \%$ & - & & \\
\hline
\end{tabular}

No of dogs infected with helminths $=58$

Overall prevalence of helminths in dogs $=58 / 103(56.31 \%)$

\section{DISCUSSION}

The study recorded high prevalence rates of GIT helminths in both humans and dogs at $76 \%$ and $56 \%$ respectively. The high prevalence in humans has confirmed the endemic nature and the burden of these infections in Makurdi, Nigeria, as has been reported (Hotez et al, 2011). The prevalence rate in humans was higher than reports by Odinaka et al. (2015) and Abah and Arene (2015) from Imo and Rivers States respectively. The prevalence in dogs has demonstrated that dogs can potentially contaminate the environment leading to transmission to humans. The prevalence rate in dogs was higher than that reported by Onyeabor (2014) in Umuahia, Abia State but similar to the report by Kutdang et al. (2010) in Jos, Plateau State.

Chi-square analysis of the entire data from the retrospective study showed that sex, ethnicity and age were not significant factors on the prevalence $(\mathrm{p}>0.05)$. However, the test of individual factor (coefficient) on specific GIT helminths showed that hookworms, Ascaris lumbricoides, Taenia spp and Strongyloides stercolaris 
prevalence depended one age. The dependence on age is consistent with the epidemiology of GIT soiltransmitted helminthes in the tropics (Hotez et al., 2008) and demonstrates the need to carry out studies on individual helminthes infections in other to bring out the effects of various factors. The dependence on age maybe because children have more access to the soil from playing and observe less hygienic practices. Ascaris lumbricoides prevalence was also shown to be statistically dependent on ethnicity $(\mathrm{p}>0.05)$. Sampling bias on children of poor Tiv ethnic group could have accounted for this since the FMC is in Makurdi where children of poor Tiv ethnic group have access.

The finding by the study that hookworms, ascariasis, trichuriasis, schistosomiasis and taeniasis were identified in humans with hookworms being the most prevalent underlines the position of Nigeria as the leading subSaharan African country with the greatest burden of disease from soil transmitted helminths as reported by Hotez and Karmath, (2009), and Hotez, (2011). The high prevalence may be due to the moist sandy nature of Makurdi soils which reportedly favours larval transmission and the high population of dogs. (Omudu et al.,2010; Hotez, 2011; Babamale etal., 2015; Babamale and Ogbomoiko, 2016) which supports zoonotic transmission. The helminths identified were similar to the ones in dogs and from other reports. (Hotez etal., 2007; Hotez, 2011; Babamale etal., 2015; Babamale and Ogbomoiko, 2016), and were zoonotic in nature as reported by Abere et al (2013).

The study has reported a high prevalence of similar GIT helminths in man and dogs with hookworms being the most prevalent infection.in Makurdi, Nigeria. We therefore concluded that dogs have a significant potential in the transmission of the infections to humans. Also, individual studies of different GIT helminths are necessary to elucidate each helminths epidemiology. Control of the infections in dogs is essential to reducing the burden of infections in man. We recommend large scale annual mass de-worming campaigns and echo Hotez (2011) call of linking neglected tropical disease to malaria and HIV/AIDS initiatives in Nigeria.

\section{REFERENCES}

[1]. Abah, A.E. and Arene, F.O.I. (2015). Status of intestinal parasitic infections among primary school. Journal of parasitological Research, Artide ID937096, Hindawi Publishing Corporation, 7pp. Available at:http://dx.doi.org/10.115/2015/937096.

[2]. Abere. T., B. Boagale, and A. Melaku, 2013. Gastrointestinal helminth parasites of pet and stray dog as a potential risk for human health in Bahir Dar Town Ethiopia. Vet World, 6(7):388-392.

[3]. Amaechi, O. (2014). Prevelence of Gastrointestinal Helmeimths of dogs: A Retrospective Study. Journal of Veterinary Advances 4 (11): $746-751$.

[4]. Babamale, A. O., Ugbomoiko, U. S., Nurudeen, S. A. and Rakuyat, O. H. (2015). Hookworm infections among the school-aged children in Okuta Community, Kwara State, Nigeria. Nigerian Journal of

[5]. Parasitology 36 (1): 33-37.

[6]. Babamale, A. O. and Ogbomoiko, U. S. (2016). Hookworm infection: A severe health problem in peri-urban community of North Central, Nigeria.Tropical Biomedicine 33 (1): 8-13.

[7]. Bowman, D.D., Montgomery, S.P., Zajac, A.M., Eberhard, M. L. and Kazacos K. R. (2010). Hookworm of dogs and cats as agents of cutaneous larva migrans. Trends in Parasitology, 26:162-167.

[8]. Deplazes, P., van Knapen, F., Sehweiger, A. and Overgaauw, P. A. (2011). Role of pet dogs and cats in the transmission of helminthic zoonoses, echinococcosis and toxocariosis. Veterinary Parasitology, 182 (1):41-53.

[9]. Hotez, P. J., Molyneux, D. H., Fenwick, A., Kumaresan, J., Sachs, S. E., Sachs, J. D. and Savioli, L. (2007). Control of Neglected Tropical Diseases. The New England Journal of Medicine, 357: 1018-1027.

[10]. Hotez, P.J., Bridley, P.J., Bethony, J.M., King, C.H., Pearce, E.J. and Jacobson, J. (2008). Helminth Infection: the great neglected tropical diseases. The Journal of Clinical Investigations, 118(4):1311-1321.

[11]. Hotez, P.J. and Kamath,A. (2009). Neglected tropical diseases in sub- Saharan Africa: review of their prevalence, distribution and diseases burden. PLOS Neglected Tropical Diseases, vol 3, e412.

[12]. Hotez, P. J. (2011). The development impact of the neglected tropical diseases (NTDs). UN Expert Paper 2011/1. Available at:https://www.un.org/en/development/desa/population/publications/pdf/expert/2011-1-hotez.pdf

[13]. Kudang, E T. Bukbak, D. N. and Ajayi, A. A. (2010). The prevalence of intestinal helminthes of dogs (Canis familaris) in Jos, Plateau State, Nigeria. Researcher 2 (8); 2010.

[14]. Mwangi. T. W.., Bethony, J. M., Brooker, S. (2006). Malaria and helminth interactions in humans: an epidemiological viewpoint. Annals of Tropical Medicine and Parasitology, 100:551-570.

[15]. Odinaka, K.K., Nwosila, E.C., Mbanefo, F., Iheakararn, A.C. and Okolo, S. (2015). Prevalence and pattern of soil transmitted helminthic infection among primary school children in a rural community in Imo State, Nigeria. Journal of Tropical Medicine, Artide ID 4PP. Available at:http://dx.doi.org/10.1155/20.5/349439.

[16]. Ogbolu, D. O., Alli, O. A., Amoo, A. D., Olao-Sun, I. I., Ilozavbie, G. W. and Olusoga-Ogbolu, F.F. (2011). High level parasitic contamination of soil sampled in Ibadan metropolis. African Journal of Medical Science, 40321-325.

[17]. Thrushfield, M. (1995). Veterinary Epidemiology ( $2^{\text {nd }}$ Ed). Blackwell Science, Oxford, London, England

[18]. Traversa, D., di Regalbono, A. F., di Cesare, A., La Torre, F., Drade, J. and Pietrobelli, M. (2014). Environmental contamination by canine geohelminths. Parasites and Vectors, 7:67-95

[19]. Usip, L.P.E. and Mathew, E. E. (2015). The prevalence of intestinal helminthes and efficacy of anthelmintic (Pyrantel) drug among primary school children in Obot Akara local government area, Akwa Ibom State, Nigeria. Peek Journal of Public Health and Management, 3 (3): 46-55

[20]. Zajac, A.M. and Conboy, G.A. (2012). Alcal examination for the diagnosis of parasitism In: Veterinary Clinical Parasitology ( $8^{\text {th }}$ Ed). Wiley-Blackwell Publishers, Iowa, USA 